\title{
Phase II study of the PI3K inhibitor BKM120 in patients with advanced or recurrent endometrial carcinoma: a stratified type I-type II study from the GINECO group
}

\author{
P-E Heudel ${ }^{\star}, 1$, M Fabbro ${ }^{2}$, C Roemer-Becuwe ${ }^{3}$, M C Kaminsky ${ }^{4}$, A Arnaud ${ }^{5}$, F Joly ${ }^{6}$, S Roche-Forestier ${ }^{7}$,

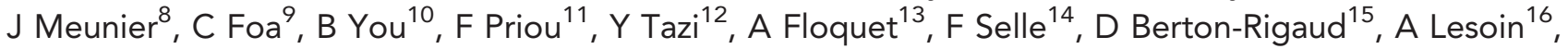 \\ E Kalbacher ${ }^{17}$, A Lortholary ${ }^{18}$, L Favier ${ }^{19}$, I Treilleux ${ }^{1}$ and I Ray-Coquard ${ }^{1,20}$
}

\begin{abstract}
Backround: Patients with metastatic endometrial carcinoma have a poor prognosis and PIK3CA mutations and amplifications are common in these cancers. This study evaluated the efficacy and safety of the pure PI3K inhibitor BKM120 in advanced or recurrent endometrial carcinoma.
\end{abstract}

\begin{abstract}
Methods: This phase II, multicentre, single-arm, double strata (histological low grade (LG) or high grade (HG)) open-label study enrolled patients with histologically confirmed advanced or recurrent endometrial carcinoma who had received not more than one prior chemotherapy regimen. Patients received initially BKM120 $100 \mathrm{mg}$ tablets once daily. Primary end points were proportion of patients free of progression at 2 months (HG strata) or at 3 months (LG strata), objective response rate (ORR), and safety.

Results: A total of 40 patients were enrolled, of whom 16 patients had received BKM120 at $100 \mathrm{mg}$. Because of high toxicities (cutaneous rash (54\%), depressive events (47\%), and anxiety (40\%), the IDMC has proposed to stop recruitment at $100 \mathrm{mg}$ and to continue the clinical trial with a lower dose of $60 \mathrm{mg}$ per day. In addition, 24 patients (median age 67 years old) were newly enrolled (14 in the LG strata and 10 in the HG strata). Rate of nonprogression at 2 months in the HG strata was $70 \%$ and at 3 months was $60 \%$ in the LG strata. Median progression-free survival (PFS) for all patients is 4.5 months (Cl 95\% 2.8-6.1), and the median PFS for LG strata is 8.3 months compared with 3.8 months for the HG strata. No response was reported. At 60 mg per day, the most commonly reported treatment-related adverse events (AEs) were hyperglycaemia (58\%), cognitive (31\%), digestive (28\%), hepatic liver functions (26\%), and rash (23\%). The most commonly reported treatment-related grade $\geqslant 3$ AEs were HTA (17\%), hyperglycaemia (17\%), and increased alanine aminotransferase (24\%). Five patients (21\%) stopped BKM120 for toxicity.
\end{abstract}

Conclusions: The BKM120 was associated with an unfavourable safety profile and minimal antitumour activity in monotherapy in advanced or recurrent endometrial carcinoma. The clinical trial was stopped before end of recruitment for toxicity.

Endometrial cancer is the most common gynaecologic malignancy and the fourth most common cancer in European and North American women, accounting for $\sim 6 \%$ of new cancer cases and $3 \%$ of cancer deaths per year (Ferlay et al, 2010). Approximately $75 \%$ of endometrial cancer cases are diagnosed with the tumour confined to the uterine corpus, but after primary surgery, $20 \%$ of these tumours recur and have limited response to systemic therapy.
The 5-year survival rate for women with advanced stage III or IV disease is $57-66 \%$ and $20-26 \%$, respectively (Creasman et al, 2006). Endometrial cancers are commonly classified into 2 histologic subtypes: endometrioid (type I), accounting for $60-70 \%$ of endometrial cancers and nonendometrioid (type II; 30-40\%). Several studies have correlated progression-free survival (PFS) to hormonal agents with tumour grade (Decruze and Green, 2007).

*Correspondence: Dr P-E Heudel; E-mail: pierre-etienne.heudel@lyon.unicancer.fr

Received 13 June 2016; revised 14 November 2016; accepted 4 December 2016; published online 10 January 2017

(c) 2017 Cancer Research UK. All rights reserved 0007 - 0920/17 
Thigpen et al (1986) in a GOG study showed that median survival durations were also significantly longer for patients with grade 1 tumours than for those with grade 3 tumours (18.8 and 6.9 months, respectively). Type I endometrial cancers are oestrogen dependent with high expression of oestrogen (ER) and progesterone (PR) receptors, exhibit microsatellite instability, frequent lossof-function mutations in the PTEN (phosphatase and tensin homologue) tumour suppressor gene (in up to $80 \%$ of endometrioid cancers), and mutational activation of the PI3K pathway (PIK3CA mutations: 36-52\%; PIK3R1 mutations: 21-43\%). Type II cancers more frequently show p53 mutations and HER2 amplification (27-44\% of type II tumours) (Murali et al, 2014).

Therapies for advanced and recurrent disease are rarely curative, median overall survival being $\sim 12$ months. Cytotoxic chemotherapy (mostly anthracyclins, platinum salts and taxanes) is indicated as frontline treatment for the majority of women with metastatic or recurrent disease (Humber et al, 2007; Pectasides et al, 2008). Hormonal treatment is a particularly attractive option for the treatment of advanced endometrial cancer for patients with lowgrade endometrial tumours, and those presenting with an asymptomatic indolent recurrence (Rose et al, 2000).

Targeted therapies, which specifically inhibit molecular abnormalities, have emerged as a novel approach and may provide improved efficacy and safety for recurrent or metastatic endometrial cancer. The phosphatidylinositol 3-kinase (PI3K)/Akt/ mammalian target of rapamycin (mTOR) pathway is frequently overactivated in endometrial cancer, making it an attractive treatment target. Activating mutation or amplification of PIK3CA is observed in $27 \%$ to $52 \%$ of endometrial cancers (Rudd et al, 2011; Konopka et al, 2011). Importantly, low expression of the tumour suppressors PTEN, TSC2, and LKB1 has been associated with $\mathrm{PI} 3 \mathrm{~K} / \mathrm{mTOR}$ pathway activation in endometrial cancer (Salvesen et al, 2004). There is increasing evidence suggesting that the PI3K/Akt pathway plays an important role in survival. A variety of pathway inhibitors have been demonstrated to interact with the PI3K signalling cascade, lacking or losing inhibition of this pathway in tumours with constitutive activation of the respective target receptors. Previous clinical trials reported activity with mTOR inhibitors in relapsed endometrial carcinoma (Slomovitz et al, 2012; Ray-Coquard et al, 2013). Constitutive activation of the PI3K pathway was found to be involved in this phenomenon, suggesting that PI3K inhibition could be a potentially useful strategy to overcome resistance towards certain receptor-targeted therapies. However, at this date, no direct correlation exists between PI3K/Akt activation and mTOR activity inhibitors in endometrial cancer as other cancers subtypes. BKM120 (buparlisib) is an oral pure PI3K inhibitor with broad antitumour activity in preclinical and in a phase I clinical study (Bendell et al, 2012).

The objective of this French multicentre phase II study (ClinicalTrials.gov identifier NCT01397877) was to assess the efficacy and safety of BKM120 (buparlisib) monotherapy in women with advanced or metastatic endometrial cancer.

\section{MATERIALS AND METHODS}

Patients. Patients eligible for study inclusion were aged $>18$ years with histologically confirmed, metastatic or locally advanced endometrial adenocarcinoma not amenable to potentially curative treatment with local surgery and/or radiation therapy who received no more than one prior chemotherapy regimen. Previous adjuvant phase with chemotherapy and radiotherapy was authorised, if interval-free survival was $>12$ months between the end of chemotherapy and relapse. Additional inclusion criteria included at least one metastatic lesion located outside previously irradiated zones and measurable according to the Response Evaluation Criteria In Solid Tumours, version 1.0 (RECIST 1.0) (Therasse et al, 2000); Eastern Cooperative Oncology Group performance status $<2$ and adequate bone marrow, and hepatic and renal function. Exclusion criteria included uncontrolled cerebral metastases; other serious or uncontrolled medical conditions; history of other cancer, except adequately treated cervical carcinoma in situ or basal or squamous cell carcinoma; and previous PI3K inhibitor treatment. All patients provided written informed consent. The study was approved by a central ethics committee and conducted in accordance with international standards of good clinical practice and all local laws and regulations.

Histological subgroups. Recently, new prognosis and predictive factors for efficacy of treatments and survival are published and defined histological type I vs type II (Llobet et al, 2009). This stratified analysis of endometrial carcinoma has major importance looking at targeted therapies involving ER, PR, or PI3K pathway (Ali, 2000). A centralised histological analysis was required to confirm diagnosis and to define tumour grade. According to this result, eligible patients were included in double strata; histological low grade in strata 1 (endometrioid grade I and II, mucinous) and high grade in strata 2 (serous, endometrioid grade III, clear cell, carcinosarcoma, and undifferentiated carcinoma).

Treatment. All patients received BKM120 (buparlisib) $100 \mathrm{mg}$ daily (2 tablets of $50 \mathrm{mg}$ ) until progression or unacceptable toxicity. In the case of adverse events (AEs) or toxicity thought to be related to BKM120, buparlisib dosing could be delayed or reduced according to an algorithm outlined in the study protocol. For grade 3 and recurrent grade 2 toxicities, BKM120 could be reduced to $80 \mathrm{mg}$ daily (first appearance of toxicities) and then $60 \mathrm{mg}$ daily (second episode of toxicity).

Because of high rate of grade 3/4 toxicities, the Independent Data Monitoring Committee (IDMC) proposed to stop recruitment at $100 \mathrm{mg}$ after recruitment of 16 patients (in July 2012) and to continue with a lower dose of $60 \mathrm{mg}$ per day (from February 2013). Then, patients received BKM120 $60 \mathrm{mg}$ daily (1 tablet of $50 \mathrm{mg}$ and 1 tablet of $10 \mathrm{mg}$ ) until progression or unacceptable toxicity. For grade 3 and recurrent grade 2 toxicities, BKM120 could be reduced to $50 \mathrm{mg}$ daily (first appearance of toxicities) and then $40 \mathrm{mg}$ daily (second episode of toxicity).

Methods. Tumour measurements included X-ray and/or computed tomography (CT) scan of the chest and abdominal and pelvic CT scan or magnetic resonance imaging. Measurements were performed at screening, every 3 months for patients with lowgrade tumours, and every 2 months for patients with high-grade tumours, during treatment and follow-up, and at the time of treatment discontinuation. Safety assessment included monitoring and recording of all AEs, regular laboratory evaluations of haematology and clinical chemistry, regular measurement of vital signs, performance of physical examinations, and recording of all concomitant medications. The AEs and laboratory abnormalities were graded according to the National Cancer Institute Common Terminology Criteria for Adverse Events, version 3.0.

Statistical analysis. The primary study end point was rate of nonprogression at 3 months (12 weeks) for patients with low-grade tumours (strata 1 ) and at 2 months (8 weeks) for patients with high-grade tumours (strata 2). Secondary end points included objective response rate (RECIST criteria) PFS at 6 months; clinical benefit, duration of clinical benefit, and time to second-line treatment (chemotherapy or hormonal therapy); overall survival (OS); safety and toxicity; surrogate markers of efficacy (biologic, pharmacokinetic); molecular analysis and correlation for response and PFS by strata. The duration of response was defined as the time from the date of the first confirmed response to the date of disease progression or death because of cancer; PFS was defined as 
the time from enrolment to the date of disease progression or death because of any cause; and OS was defined as the time from enrolment to the date of death because of any cause.

This study was designed using a Simon two-stage mini-max design (Simon, 1989) To show a $>70 \%$ success rate (i.e., $>70 \%$ of patients without progressive disease at 3 months for strata 1 and 2 months for strata 2) with $90 \%$ power and $\alpha=5 \%, 24$ evaluable patients were required by strata. In stage one of the study and for each strata, if at least 5 of the first 10 evaluable patients demonstrated complete response (CR), partial response (PR), or stable disease (SD), recruitment was continued until 24 evaluable patients were enrolled. In stage two, if at least 14 patients demonstrated $\mathrm{CR}, \mathrm{PR}$, or $\mathrm{SD}, \mathrm{BKM} 120$ was considered to have shown sufficient efficacy to warrant further study. Kaplan-Meier methodology was used to estimate PFS and OS. Progression-free survival and OS equality in subgroups was assessed using the logrank test. The protocol-specified population evaluable for nonprogressive disease included all enrolled patients who had no protocol deviations and received BKM120 for $>1$ month according to the study protocol. The protocol-specified safety population and the population evaluable for clinical benefit included all patients who received $>1$ dose of study drug.

\section{RESULTS}

Between December 2011 and January 2014, 40 patients were enrolled at 13 French centres. At the time of analysis, 38 patients had discontinued treatment owing to adverse events (36.8\%) and progressive disease (63.2\%). Between stages BKM120 $100 \mathrm{mg}$ and BKM120 $60 \mathrm{mg}$, enrolment was stopped during 7 months.

Results with BKM120 $100 \mathrm{mg}$ daily. A total of 16 patients were included at $100 \mathrm{mg}$ daily. Because of high rate of grade $3 / 4$ toxicities (cutaneous rash (54\%), depressive events (47\%), and anxiety $(40 \%))$, the IDMC proposed to stop recruitment at $100 \mathrm{mg}$ but to continue the recruitment with a lower dose of $60 \mathrm{mg}$ per day. At $100 \mathrm{mg}$ per day, 9 patients (56\%) stopped BKM120 for toxicity. Median time of toxicity apparition was 58.5 days (range 14-147 days). Median duration of BKM120 exposure was 34 days (9-753 days). Of the 16 included patients, 7 were evaluable for primary end point: 4 stable disease ( 2 at 3 months, and 2 at 2 months) 2 progressions, and 1 death.

Results for BKM120 $60 \mathrm{mg}$ daily. At this level dose, 24 patients were included. Patient characteristics are summarised in Table 1. Median age was 67.1 years (range $50-80$ years) and $71 \%$ of patients had endometrioid carcinomas. In addition, 14 patients (58\%) were included in strata 1 (low grade) and 10 patients (42\%) in strata II (high grade). The treatment-free interval was 16.1 months (range 0.7-22.5 months) and a majority of patients were previously treated with surgery $(83 \%)$. The median duration of treatment was 3.7 months (range 14 days to 12.2 months).

Efficacy. Concerning the primary study end point, the rate of nonprogression at $3(\operatorname{arm} 1)$ or 2 (arm 2) months was 65\% (IC95 (44-86)) with $60 \%$ for strata I (low-grade tumour) and $70 \%$ for strata II (high-grade tumour). Median PFS and OS for all patients were 4.5 months (CI 95\% 2.8-6.1) and 10.1 months (CI 95\% not feasible) respectively; median PFS for LG strata was 8.3 months (CI 95\% 5.8-10.8) compared with 3.8 months (CI 95\% 3.0-4.6) for the HG strata (Figure 1). No objective response was reported. Six patients (25\%) received $<3$ months of treatment because of a rapid progressive disease, whereas 4 patients were not evaluable for efficacy because of a very early medical withdrawal due to toxicity. In strata I, 6 patients experienced long-term stability disease (i.e., > 6 months) (range 7-13.4 months). These six patients had an endometrioid grade I/II carcinoma and five patients had never received chemotherapy. Median duration between initial therapeutic management and metastatic relapse was 27.4 months.

Safety. Median duration of BKM120 (60 mg daily) exposure was 3.7 months (range 14 days to 12.2 months). Of the patients, $87 \%$ experienced grade $3 / 4$ toxicity. Five patients $(21 \%)$ received $<3$ months of treatment owing to toxicity. Only 13 patients (54\%) received BKM120 for $>3$ months, and 8 patients had their treatment discontinued to toxicity, and among them 6 patients continued treatment with dose reduction. The most common causes of dose reduction or interruption were hepatic cytolysis and hyperglycaemia. Median time for toxicity apparition was 69.5 days (range 14 days to 350 days).

Of the 24 patients included at this level dose, all experienced at least one $\mathrm{AE}$, a majority of which were of grade 1 or 2 severity. The most common nonbiological all-grade AEs were fatigue (74\%), cutaneous rash (55\%), depression (42\%) abdominal pain $(41 \%)$, and diarrhoea (37\%) (Table 2). The most common grade $3 / 4$ AEs were hypertension $(17 \%)$, cutaneous rash $(13 \%)$, and fatigue $(8 \%)$. The most common biological all-grade AEs were hepatic cytolysis defined by increased alanine aminotransferase (ALT) or aspartate aminotransferase (AST) (86\%), lymphopenia (47\%), hyperglycaemia (67\%), and hypercholesterolaemia (61\%) (Table 3). A total of 259 AEs were experienced by 24 patients (100\%) including 31 serious AEs for 18 patients (75\%). Of these serious AEs, 25 (45\%) were considered to be related to study drug. The most common serious AEs were reduced general condition (nine events), thrombosis (six events), infection and interstitial lung disease (four events for each), and hyperglycaemia and renal insufficiency

Table 1. Patient characteristics

\begin{tabular}{|c|c|c|c|c|}
\hline & $\begin{array}{l}\text { Cohort } 60 \mathrm{mc} \\
\quad(n=24)\end{array}$ & & $\begin{array}{c}\text { Cohort 100n } \\
(n=16)\end{array}$ & \\
\hline Patient characteristics & $N$ & $\%$ & $N$ & $\%$ \\
\hline Median age, years (range) & $67.1(50.0-79.7)$ & & $65.2(53.6-79.5)$ & \\
\hline $\begin{array}{l}\text { Eastern Cooperative Oncology } \\
\text { Group Performance Status } \\
0 \\
1 \\
2 \\
\text { Missing }\end{array}$ & $\begin{array}{l}10 \\
14 \\
- \\
-\end{array}$ & $\begin{array}{l}42 \\
58 \\
- \\
-\end{array}$ & $\begin{array}{l}7 \\
6 \\
2 \\
1\end{array}$ & $\begin{array}{c}44 \\
38 \\
12 \\
6\end{array}$ \\
\hline $\begin{array}{l}\text { Histological type } \\
\text { Endometrioid } \\
\text { Serous } \\
\text { Carcinosarcoma }\end{array}$ & $\begin{array}{c}17 \\
2 \\
5\end{array}$ & $\begin{array}{c}71 \\
8 \\
21\end{array}$ & $\begin{array}{c}13 \\
1 \\
2\end{array}$ & $\begin{array}{c}81 \\
6 \\
13\end{array}$ \\
\hline $\begin{array}{l}\text { Strata } \\
\text { Strata I (endometrioid/ } \\
\text { mucinous grade } 1 \text { or 2) } \\
\text { Strata II (high grade) }\end{array}$ & $\begin{array}{l}14 \\
10\end{array}$ & $\begin{array}{l}58 \\
42\end{array}$ & $\begin{array}{l}7 \\
9\end{array}$ & $\begin{array}{l}44 \\
56\end{array}$ \\
\hline $\begin{array}{l}\text { Disease } \\
\text { Initial metastatic disease } \\
\text { Relapse }\end{array}$ & $\begin{array}{c}9 \\
15\end{array}$ & $\begin{array}{l}38 \\
62\end{array}$ & $\begin{array}{l}9 \\
7\end{array}$ & $\begin{array}{l}56 \\
44\end{array}$ \\
\hline $\begin{array}{l}\text { Metastatic sites } \\
\text { Lung } \\
\text { Nodes } \\
\text { Peritoneal } \\
\text { Uterus } \\
\text { Pelvis } \\
\text { Liver } \\
\text { Other sites }\end{array}$ & $\begin{array}{l}12 \\
11 \\
6 \\
5 \\
7 \\
2 \\
6\end{array}$ & \begin{tabular}{c|}
50 \\
47 \\
25 \\
21 \\
29 \\
8 \\
25
\end{tabular} & $\begin{array}{c}10 \\
11 \\
3 \\
4 \\
5 \\
5\end{array}$ & $\begin{array}{l}63 \\
69 \\
19 \\
25 \\
- \\
31 \\
31\end{array}$ \\
\hline $\begin{array}{l}\text { Treatment-free interval } \\
\text { Months, range }\end{array}$ & $16.1(0.7-22.5)$ & & $26.0(14.6-51.6)$ & \\
\hline $\begin{array}{l}\text { Prior treatment } \\
\text { Surgery } \\
\text { Hormonal therapy } \\
\text { Radiation therapy } \\
\text { Chemotherapy first line }\end{array}$ & $\begin{array}{c}20 \\
1 \\
8 \\
8\end{array}$ & $\begin{array}{c}83 \\
4 \\
33 \\
33\end{array}$ & $\frac{11}{5}$ & $\begin{array}{l}69 \\
-31 \\
19\end{array}$ \\
\hline
\end{tabular}


(three events for each). Eleven patients (25\%) died during the study. Of these deaths, 10 were related to disease progression.

\section{DISCUSSION}

In this French phase II of the GINECO group, multicentre, singlearm study, BKM120 was associated with an unfavourable safety profile for endometrial cancer patients and showed a minimal antitumour activity in monotherapy in this population, except for low-grade endometrioid tumours. The clinical trial was stopped before the end of recruitment for toxicity.

Interestingly, the safety profile of BKM120 is significantly different depending on the primary tumours sites and even histological types. For example, in lung cancers, the most common grade 3/4 AEs related to BKM120 (100 mg by day) were hyperglycaemia $(23.3 \%)$, asthenia, and fatigue (6.7\% each) for patients with squamous carcinomas, and increased ALT (15.2\%), increased aspartate AST, hyperglycaemia (12.1\% each), asthenia, and rash (6.1\% each) for nonsquamous carcinomas (Vansteenkiste et al, 2015). A phase Ib study of BKM120 (100 mg daily) with letrozole in ER-positive metastatic breast cancer has shown a safe combination with reversible toxicities. Grade 3 AEs, regardless of causality, were observed in $27 \%$ of patients. No grade $4 \mathrm{AE}$ was observed. The most common grade 3 AEs were transaminase elevation (15\%), fatigue (5\%), rash (5\%), and depression (5\%) (Mayer et al, 2014). The BKM120 is associated with several potential toxicities, some of which are shared by the class of this agent. For example, the role of the PI3K/Akt/mTOR signalling pathway in regulating glucose metabolism can explain hyperglycaemia. Cutaneous rash have been attributed to cytokine
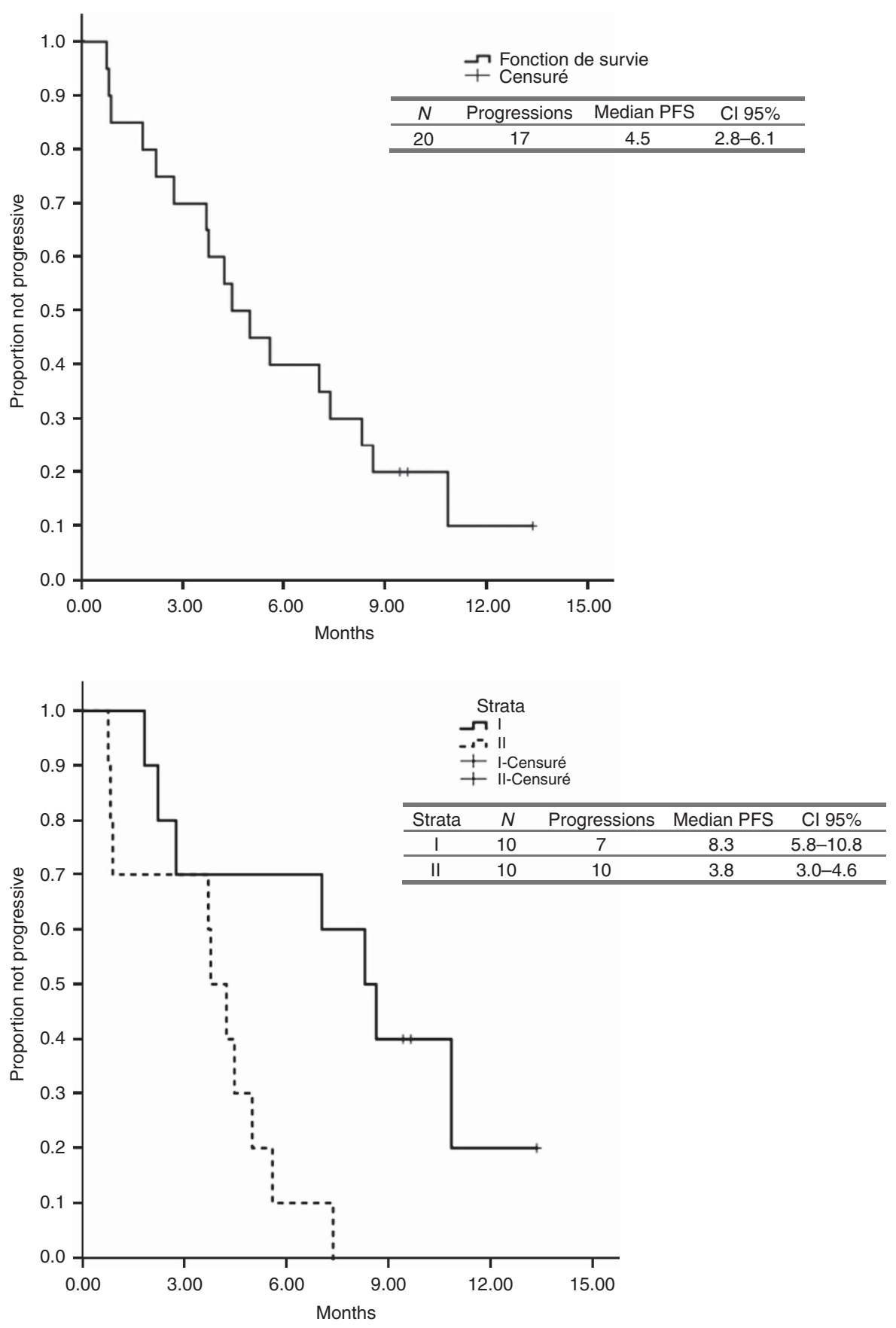

Figure 1. Overall and stratified progressive-free survival. 
and chemokine deregulation resulting from pathway inhibition (Chia et al, 2015). Greater intensity and frequency of side effects in endometrial cancer may be explained by patients' physiological characteristics but also may be a different PI3K/AKT/mTOR pathway deregulation.

The PTEN is a tumour suppressor gene. Mutations or loss of function in PTEN plays a significant role in the pathogenesis of endometrial cancer (Ali, 2000). Loss of PTEN expression or increased PIK3CA expression activates AKT that leads to increased activity of mTOR, causing cell proliferation. The first generation of mTOR inhibitors that is currently being evaluated for clinical trials in patient with advanced or recurrent endometrial cancer included everolimus, temsirolimus, and ridaforolimus (Table 4). However, mTOR inhibitors have shown modest therapeutic efficacy in monotherapy, but interestingly, an interesting signal for low-grade endometrioid tumours as in the present study. Ray-Coquard et al (2013) showed partial response in three patients (11\%) with lowgrade tumour (Trédan et al, 2013) similar to Oza et al (2011) who observed 4 of 7 partial response (57\%) for endometrioid low-grade tumours. Table 4 reported all data using mTOR inhibitor in endometrial carcinoma. As mTOR inhibitors represented the first generation of targeted therapies, exploring new compounds as PI3K inhibitors seemed an important issue on endometrial carcinoma. Moreover, Pilaralisib, a PI3K inhibitor, was associated with a favourable safety profile and minimal antitumour activity (rate of PFS $>6$ months was 11.9\%) in phase II, multicentre, single-arm study that enrolled patients with metastatic endometrial carcinomas (Matulonis et al, 2015).

The next step was to explore combination with hormonal therapies. In breast cancer, clinical data suggest that use of mTOR inhibitors can overcome acquired resistance to aromatase-inhibitor therapy (Bachelot et al, 2012). Specifically in endometrial cancer, there are in vitro data that $\mathrm{mTOR}$ inhibitors increase progesterone messenger RNA (mRNA) expression (Bae-Jump et al, 2010). Two phase II trials combining mTOR inhibitors with hormonal therapy have been completed in endometrial cancer. The GOG-0248 is a randomised phase II trial in women with hormone therapy-naive

Table 2. Nonbiological AEs (cohort $60 \mathrm{mg}$ )

\begin{tabular}{|l|c|c|}
\hline $\begin{array}{l}\text { Nonbiological grade } \\
\text { (CTCAE v4.03) }(\boldsymbol{n}=\mathbf{2 4})\end{array}$ & Grade 1-2 & Grade 3-4 \\
\hline Cutaneous rash & $10(42 \%)$ & $3(13 \%)$ \\
\hline Mucositis & $5(21 \%)$ & $1(4 \%)$ \\
\hline Nausea & $8(33 \%)$ & - \\
\hline Vomiting & $5(21 \%)$ & - \\
\hline Constipation & $9(37 \%)$ & - \\
\hline Diarrhoea & $9(37 \%)$ & - \\
\hline Abdominal pain & $8(33 \%)$ & $2(8 \%)$ \\
\hline Anorexia & $8(33 \%)$ & $1(4 \%)$ \\
\hline Intestinal perforation & - & $1(4 \%)$ \\
\hline Hypertension & $1(4 \%)$ & $4(17 \%)$ \\
\hline Dyspnoea & $4(17 \%)$ & $1(4 \%)$ \\
\hline Depression & $10(42 \%)$ & - \\
\hline Anxiety & $5(21 \%)$ & - \\
\hline Fatigue & $16(66 \%)$ & $2(8 \%)$ \\
\hline Infection without neutropenia & $5(21 \%)$ & $1(4 \%)$ \\
\hline Change of the general state & - & $2(8 \%)$ \\
\hline Pains & $11(46 \%)$ & - \\
\hline Lymphangitis & - & $1(4 \%)$ \\
\hline $\begin{array}{l}\text { Abbreviations: AE = adverse event; CTCAE }=\text { Common Terminology } \\
\text { Events. }\end{array}$ & & \\
\hline
\end{tabular}

disease (only one prior chemotherapy regimen permitted). Patients received temsirolimus alone or concomitantly with MEGACE alternating with TAMOXIFENE. The arm with the combined regimen closed rapidly because of an unacceptable rate (32\%) of venous thrombosis (7 in 22 patients) (Fleming et al, 2014). The second trial is an open-label, single-arm phase II study in patients with recurrent endometrial cancer who had received two or fewer prior chemotherapeutic regimens. Patients received the combination of letrozole and everolimus. Of the 35 patients, 11 (31\%) had an objective response and 14 of 35 patients (40\%) had a clinical benefit, defined as CR, PR, or SD for at least 8 weeks. None of the patients discontinued treatment as a result of toxicity (Slomovitz et al, 2015). All these data suggested clearly a potential effect targeting this pathway. However, monotherapy seems not to be the best strategy and combination might be an alternative.

Because of the data published on cross-talk between signal transduction pathways, particularly ER signalling and the PI3K/ Akt/ mTOR pathway (Bachelot et al, 2012), combination with hormonal therapy needs to be also explored for endometrial carcinoma. In order to explore this hypothesis, a French multicentric randomised open-label phase I/II evaluating AZD2014 (dual mTORC1/mTORC2 inhibitor) in combination with anastrozole from the CLIP-GINECO group will open beginning in 2016 for the treatment of metastatic hormone receptor-positive endometrial adenocarcinoma.

Overall, results from this study demonstrate that BKM120 has an unfavourable risk-benefit ratio in women with advanced or metastatic refractory endometrial cancer. The positive signal for low-grade endometrioid tumours and results of previous clinical trials with mTOR inhibitors tend to show that inhibition of the $\mathrm{PI} 3 \mathrm{~K} / \mathrm{Akt} / \mathrm{mTOR}$ pathway may be a viable therapeutic target for a subset of patients with advanced endometrial cancer.

\section{ACKNOWLEDGEMENTS}

We thank the patients who participated in the trial and their families. We acknowledge Nicolas Gane, Carole Breuneval, Bénédicte Votan from the GINECO study office and Claire Cropet, Sylvie Chabaud from the Centre Léon Bérard (UBET). We also thank the following investigators and pharmacists who participated in the trial. INVESTIGATORS: Sophie ROCHEFORESTIER (Centre Jean Bernard - Clinique Victor Hugo, LE MANS); Sophie GOUERANT (Centre François Baclesse, CAEN); Alice LEVARD, Jean-Paul GUASTALLA (Centre Léon Bérard,

\section{Table 3. Biological AEs (cohort $60 \mathrm{mg}$ )}

\begin{tabular}{|c|c|c|}
\hline Biological grade (CTCAE v4.03) $(n=24)$ & $\begin{array}{c}\text { Grade } \\
1-2\end{array}$ & $\begin{array}{c}\text { Grade } \\
3-4\end{array}$ \\
\hline Neutropenia & $2(8 \%)$ & - \\
\hline Anaemia & $6(26 \%)$ & $1(4 \%)$ \\
\hline Lymphopenia & $10(43 \%)$ & $1(4 \%)$ \\
\hline Hepatic cytolysis & $11(47 \%)$ & $4(17 \%)$ \\
\hline \multicolumn{3}{|l|}{ (increase in ALT and/or AST) } \\
\hline Increase in PAL & $11(47 \%)$ & - \\
\hline Increase in GGT & $10(43 \%)$ & $3(13 \%)$ \\
\hline Hyperglycaemia & $12(52 \%)$ & $4(17 \%)$ \\
\hline Hypokalaemia, hypomagnesaemia, hyponatraemia & - & $1(4 \%)$ \\
\hline Hypercholesterolaemia & $14(61 \%)$ & - \\
\hline Renal toxicity & 9 (38\%) & $1(4 \%)$ \\
\hline
\end{tabular}

Abbreviations: $A E=$ adverse event; $A L T=$ alanine aminotransferase; $A S T=$ aspartate aminotransferase; $\mathrm{CTCAE}=$ Common Terminology Criteria for Adverse Events; GGT = gammaglutamyltransferase; PAL = Alkaline phosphatase. 
Table 4. Studies of mTOR inhibitors in endometrial cancer

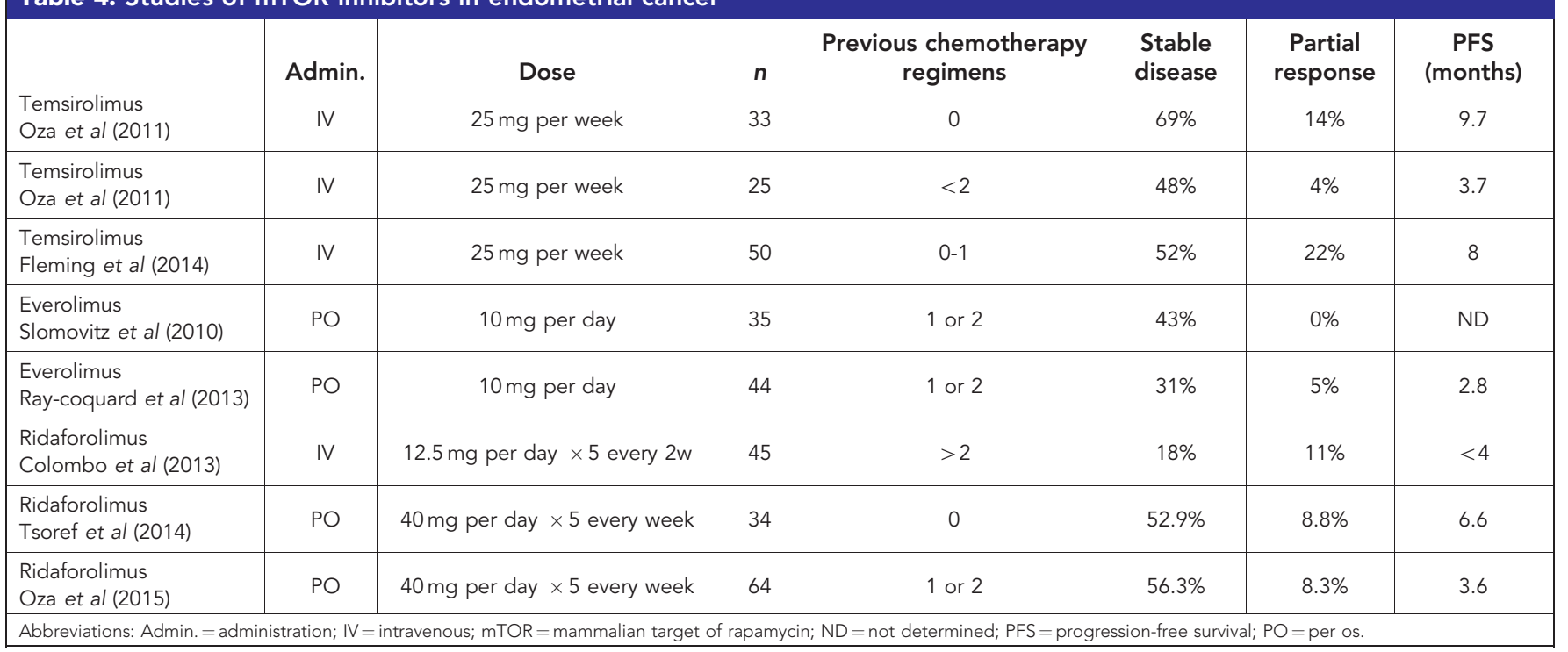

LYON); Cyril FOA (Hôpital Privé Clairval, MARSEILLE); Sophie TARTAS (Centre Hospitalier Lyon Sud, PIERRE-BENITE); JeanSébastien FRENEL (ICO Centre René Gauducheau, SAINTHERBLAIN); Youssef TAZI (Gustave Roussy, VILLEJUIF). PHARMACISTS: Chrystèle GROLLIER (Centre Jean Bernard Clinique Victor Hugo, LE MANS); Catherine VALLANCE (ICL Institut de Cancérologie de Lorraine, VANDOEUVRE-LESNANCY); Françoise DE CROZALS, Nadine PLUJA-JEAN (Institut Sainte-Catherine, AVIGNON); Pierre PLOCCO, Véronique PRIOU (Centre Hospitalier Régional d'Orléans, ORLEANS); Fabienne DIVANON (Centre François Baclesse, CAEN); Catherine ENGEL, Laurence GILLES-AFCHAIN (Centre Léon Bérard, LYON); Camille LETELLIER (Hôpital Privé Clairval, MARSEILLE); Vérane SCHWIERTZ (Centre Hospitalier Lyon Sud, PIERRE-BENITE); Martine DUBAN (Centre Georges François Leclerc, DIJON); Khebidja BEKHTARI (ICM Val d'Aurelle, MONTPELLIER); Jérôme DIMET (Centre Hospitalier Départemental Les Oudairies, LA ROCHE-SUR-YON); Barbara LORTAL (Institut Bergonié, BORDEAUX); Isabelle DEBRIX, Julie FILLON (Hôpital Tenon, PARIS); Sophie ROCHARD (ICO Centre René Gauducheau, SAINT-HERBLAIN); Jean-Louis CAZIN, Patricia GOSSELIN (Centre Oscar Lambret, LILLE); Michèle ESSERT, Virginie NERICH (Hôpital Jean Minjoz, BESANCON); Laurent GUIVARCH (Centre Catherine de Sienne, NANTES ); Raphaël ALFONSI (ORACLE - Centre d'Oncologie de Gentilly, NANCY); Sylvie DEMIRDJIAN (Gustave Roussy, VILLEJUIF). This work was supported by Novartis France and Ligue Nationale Contre le Cancer (unrestricted grant). The results were presented in part during the American Society of Clinical Oncology (ASCO) meeting in June 2015.

\section{CONFLICT OF INTEREST}

The authors declare no conflict of interest except F Joly who declares NOVARTIS board expert.

\section{REFERENCES}

Ali IU (2000) Gatekeeper for endometrium: the PTEN tumor suppressor gene. J Natl Cancer Inst 92(11): 861-863.
Bachelot T, Bourgier C, Cropet C, Ray-Coquard I, Ferrero JM, Freyer G, Abadie-Lacourtoisie S, Eymard JC, Debled M, Spaëth D, Legouffe E, Allouache D, El Kouri C, Pujade-Lauraine E (2012) Randomized phase II trial of everolimus in combination with tamoxifen in patients with hormone receptor-positive, human epidermal growth factor receptor 2-negative metastatic breast cancer with prior exposure to aromatase inhibitors: a GINECO study. J Clin Oncol 30(22): 2718-2724.

Bae-Jump VL, Zhou C, Boggess JF, Whang YE, Barroilhet L, Gehrig PA (2010) Rapamycin inhibits cell proliferation in type I and type II endometrial carcinomas: a search for biomarkers of sensitivity to treatment. Gynecol Oncol 119(3): 579-585.

Bendell JC, Rodon J, Burris HA, de Jonge M, Verweij J, Birle D, Demanse D, De Buck SS, Ru QC, Peters M, Goldbrunner M, Baselga J (2012) Phase I, dose-escalation study of BKM120, an oral pan-Class I PI3K inhibitor, in patients with advanced solid tumors. J Clin Oncol 30(3): 282-290.

Chia S, Gandhi S, Joy AA, Edwards S, Gorr M, Hopkins S, Kondejewski J, Ayoub JP, Califaretti N, Rayson D, Dent SF (2015) Novel agents and associated toxicities of inhibitors of the pi3k/Akt/mtor pathway for the treatment of breast cancer. Curr Oncol 22(1): 33-48.

Colombo N, McMeekin DS, Schwartz PE, Sessa C, Gehrig PA, Holloway R, Braly P, Matei D, Morosky A, Dodion PF, Einstein MH, Haluska F (2013) Ridaforolimus as a single agent in advanced endometrial cancer: results of a single-arm, phase 2 trial. Br J Cancer 108(5): 1021-1026.

Creasman WT, Odicino F, Maisonneuve P, Quinn MA, Beller U, Benedet JL, Heintz AP, Ngan HY, Pecorelli S (2006) Carcinoma of the corpus uteri. FIGO 26th Annual Report on the Results of Treatment in Gynecological Cancer. Int J Gynaecol Obstet 95(Suppl 1): S105-S143.

Decruze SB, Green JA (2007) Hormone therapy in advanced and recurrent endometrial cancer: A systematic review. Int J Gynecol Cancer 17: 964-978.

Ferlay J, Shin HR, Bray F, Forman D, Mathers C, Parkin DM (2010) Estimates of worldwide burden of cancer in 2008: GLOBOCAN 2008. Int J Cancer 127: 2893-2917.

Fleming GF, Filiaci VL, Marzullo B, Zaino RJ, Davidson SA, Pearl M, Makker V, Burke 2nd JJ, Zweizig SL, Van Le L, Hanjani P, Downey G, Walker JL, Reyes HD, Leslie KK (2014) Temsirolimus with or without megestrol acetate and tamoxifen for endometrial cancer: a gynecologic oncology group study. Gynecol Oncol 132(3): 585-592.

Humber CE, Tierney JF, Symonds RP, Collingwood M, Kirwan J, Williams C, Green JA (2007) Chemotherapy for advanced, recurrent or metastatic endometrial cancer: a systematic review of Cochrane collaboration. Ann Oncol 18: 409-420.

Konopka B, Janiec-Jankowska A, Kwiatkowska E, Najmola U, Bidzinski M, Olszewski W, Goluda C (2011) PIK3CA mutations and amplification in endometrioid endometrial carcinomas: relation to other genetic defects and clinicopathologic status of the tumors. Hum Pathol 42: $1710-1719$. 
Llobet D, Pallares J, Yeramian A, Santacana M, Eritja N, Velasco A, Dolcet X (2009) Molecular pathology of endometrial carcinoma: practical aspects from the diagnostic and therapeutic viewpoints. J Clin Pathol 62(9): 777-785.

Matulonis U, Vergote I, Backes F, Martin LP, McMeekin S, Birrer M, Campana F, Xu Y, Egile C, Ghamande S (2015) Phase II study of the PI3K inhibitor pilaralisib (SAR245408; XL147) in patients with advanced or recurrent endometrial carcinoma. Gynecol Oncol 136(2): 246-253.

Mayer IA, Abramson VG, Isakoff SJ, Forero A, Balko JM, Kuba MG, Sanders ME, Yap JT, Van den Abbeele AD, Li Y, Cantley LC, Winer E, Arteaga CL (2014) Stand up to cancer phase Ib study of pan-phosphoinositide-3-kinase inhibitor buparlisib with letrozole in estrogen receptor-positive/human epidermal growth factor receptor 2-negative metastatic breast cancer. J Clin Oncol 32(12): 1202-1209.

Murali R, Soslow RA, Weigelt B (2014) Classification of endometrial carcinoma: more than two types. Lancet Oncol 15(7): e268-e278.

Oza AM, Elit L, Tsao MS, Kamel-Reid S, Biagi J, Provencher DM, Gotlieb WH, Hoskins PJ, Ghatage P, Tonkin KS, Mackay HJ, Mazurka J, Sederias J, Ivy P, Dancey JE, Eisenhauer EA (2011) Phase II study of temsirolimus in women with recurrent or metastatic endometrial cancer: a trial of the NCIC Clinical Trials Group. J Clin Oncol 29: 3278-3285.

Oza AM, Pignata S, Poveda A, McCormack M, Clamp A, Schwartz B, Cheng J, Li X, Campbell K, Dodion P, Haluska FG (2015) Randomized phase II trial of ridaforolimus in advanced endometrial carcinoma. J Clin Oncol 33: 3576-3582.

Pectasides D, Xiros N, Papaxoinis G, Pectasides E, Sykiotis C, Koumarianou A, Psyrri A, Gaglia A, Kassanos D, Gouveris P, Panayiotidis J, Fountzilas G, Economopoulos T (2008) Carboplatin and paclitaxel in advanced or metastatic endometrial cancer. Gynecol Oncol 109: 250-254.

Ray-Coquard I, Favier L, Weber B, Roemer-Becuwe C, Bougnoux P, Fabbro M, Floquet A, Joly F, Plantade A, Paraiso D, Pujade-Lauraine E (2013) Everolimus as second- or third-line treatment of advanced endometrial cancer: ENDORAD, a phase II trial of GINECO. Br J Cancer 108(9): 1771-1777.

Rose PG, Brunetto VL, VanLe L, Bell J, Walker JL, Lee RB (2000) A phase II trial of anastrozole in advanced recurrent or persistent endometrial carcinoma: a Gynecologic Oncology Group Study. Gynecol Oncol 78: 212-216.

Rudd ML, Price JC, Fogoros S, Godwin AK, Sgroi DC, Merino MJ, Bell DW (2011) A unique spectrum of somatic PIK3CA (p110alpha) mutations within primary endometrial carcinomas. Clin Cancer Res 17: 1331-1340.

Salvesen HB, Stefansson I, Kretzschmar EI, Gruber P, Mac-Donald ND, Ryan A, Jacobs IJ, Akslen LA, Das S (2004) Significance of PTEN alterations in endometrial carcinoma: a population-based study of mutations, promoter methylation and PTEN protein expression. Int J Oncol 25: 1615-1623.

Simon R (1989) Optimal two-stage designs for phase II clinical trials. Control Clin Trials 10(1): 1-10.
Slomovitz BM, Lu KH, Johnston T, Coleman RL, Munsell M, Broaddus RR, Walker C, Ramondetta LM, Burke TW, Gershenson DM, Wolf J (2010) A phase 2 study of the oral mammalian target of rapamycin inhibitor, everolimus, in patients with recurrent endometrial carcinoma. Cancer 116: 5415-5419.

Slomovitz B, Levenback C, Brown J, Wolf J, Schmeler K, Johnston T, Mura D, Stone RL, Lu K, Coleman RL (2012) Everolimus and letrozole in women with previously treated recurrent endometrial cancer: a multiinstitutional phase II clinical trial. Int J Gynecol Cancer 22(Suppl 3): 8.

Slomovitz BM, Jiang Y, Yates MS, Soliman Pt, Johnston T, Nowakowski M, Levenback C, Zhang Q, Ring K, Munsell MF, Gershenson DM, Lu KH, Coleman RL (2015) Phase II study of everolimus and letrozole in patients with recurrent endometrial carcinoma. J Clin Oncol 33(8): 930-936.

Therasse P, Arbuck SG, Eisenhauer EA, Wanders J, Kaplan RS, Rubinstein L, Verweij J, Van Glabbeke M, van Oosterom AT, Christian MC, Gwyther SG (2000) New guidelines to evaluate the response to treatment in solid tumors. J Natl Cancer Inst 92: 205-216.

Thigpen JT, Blessing J, Disaia P (1986) Oral medroxyprogesterone acetate in advanced or recurrent endometrial carcinoma: results of therapy and correlation with estrogen and progesterone receptor levels. In Endocrinology and Malignancy: Basic and Clinical Issues; The Proceedings of the First International Congress on Cancer and Hormones, Iacobelli S (ed), pp 446-447. CRC Press, Parthenon Publishers: Rome.

Trédan O, Treilleux I, Wang Q, Gane N, Pissaloux D, Bonnin N, Petit T, Cretin J, Bonichon-Lamichhane N, Priou F, Lavau-Denes S, Mari V, Freyer G, Lebrun D, Alexandre J, Ray-Coquard I (2013) Predicting everolimus treatment efficacy in patients with advanced endometrial carcinoma: a GINECO group study. Target Oncol 8(4): 243-251.

Tsoref D, Welch S, Lau S, Biagi J, Tonkin K, Martin LA, Ellard S, Ghatage P, Elit L, Mackay HJ, Allo G, Tsao MS, Kamel-Reid S, Eisenhauer EA, Oza AM (2014) Phase II study of oral ridaforolimus in women with recurrent or metastatic endometrial cancer. Gynecol Oncol 135(2): 184-189.

Vansteenkiste JF, Canon JL, De Braud F, Grossi F, De Pas T, Gray JE, Su WC, Felip E, Yoshioka H, Gridelli C, Dy GK, Thongprasert S, Reck M, Aimone P, Vidam GA, Roussou P, Wang YA, Di Tomaso E, Soria JC (2015) Safety and efficacy of Buparlisib (BKM120) in patients with PI3K pathway-activated non-small cell lung cancer (NSCLC): results from the phase II BASALT-1 study. J Thorac Oncol 10(9): 1319-1327.

This work is published under the standard license to publish agreement. After 12 months the work will become freely available and the license terms will switch to a Creative Commons AttributionNonCommercial-Share Alike 4.0 Unported License.

${ }^{1}$ Department of Medical Oncology, Centre Léon Bérard, Centre de Recherche en Cancérologie de Lyon, 28 Rue Laennec, 69008 Lyon, France; ${ }^{2}$ ICM Val d'Aurelle, Parc Euromédecine 208 Rue des Apothicaires, 34298 Montpellier, France; ${ }^{3}$ ORACLE Centre d'oncologie de Gentilly, 2 Rue Marie Marvingt, 54100 Nancy, France; ${ }^{4}$ ICL Institut de Cancérologie de Lorraine, 6 Avenue de Bourgogne Brabois, 54511 Vandoeuvre-les-Nancy, France; ${ }^{5}$ Institut Sainte Catherine, 250 Chemin de Baigne-pieds, 84918 Avignon, France; ${ }^{6}$ Centre François Baclesse, Avenue du Général Harris, 14000 Caen, France; ${ }^{7}$ Centre Jean Bernard-Clinique Victor Hugo, 18 Rue Victor Hugo, 72000 Le Mans, France; ${ }^{8}$ Centre hospitalier régional d'Orléans, 14 Avenue de l'Hôpital, 45067 Orléans, France; ${ }^{9}$ Hôpital privé Clairval, 317 Boulevard du Redon, 13009 Marseille, France; ${ }^{10}$ Centre hospitalier Lyon Sud, 165 Chemin du Grand Revoyet, 69495 Pierre-Bénite, France; ${ }^{11}$ Centre hospitalier départemental Les Oudairies, Les Oudairies, 85925 La Roche-surYon, France; ${ }^{12}$ Institut de cancérologie Gustave Roussy, 114 Rue Edouard Vaillant, 94805 Villejuif, France; ${ }^{13}$ Institut Bergonié, 229 Cours de I'Argonne, 33076 Bordeaux, France; ${ }^{14}$ Hôpital Tenon, 4 rue de la Chine 75020 Paris, France; ${ }^{15}$ ICO centre René Gauducheau, Boulevard Jacques Monod, 44805 Saint Herblain, France; ${ }^{16}$ Centre Oscar Lambret, 3 Rue F. Combemale, 59020 Lille, France; ${ }^{17}$ Hôpital Jean Minjoz, 3 Boulevard Alexandre Fleming, 25030 Besançon, France; ${ }^{18}$ Centre Catherine de Sienne, 2 Rue Eric Tabarly, 44202 Nantes, France; ${ }^{19}$ Centre Georges François Leclerc, 1 Rue Professeur Marion, 21079 Dijon, France and ${ }^{20}$ UCBL Université Claude Bernard, Lyon I, Lyon, France 